\title{
Determination of various bioactive potential of stoechospermum marginatum (C. agardh) kutzing in- vitro
}

\begin{abstract}
The objective of present study was to screen the antibacterial, total antioxidant and cytotoxic properties of ethanol extract and its fractions of S. marginatum. The highest antibacterial activity was found in ethanol extract followed by dichloromethane, ethyl acetate, hexane and aqueous fractions. TAAs and RAAs were estimated along with known antioxidant such as quercetin, $\beta$-carotene and L-ascorbic acid. TAA was found to be highest in EE (22-75\%) followed by DMF (18-65\%), EAF (13-50\%), HF (8-38\%) and AF (5-31\%). R square value between concentration and TAA of extract/fractions made by linear regression clearly shows TAA dependents on the concentration. Moreover, ethanol extract exhibited cytotoxicity as equal as quercetin at their maximum concentration $(640 \mu \mathrm{g} / \mathrm{mL}$ and $160 \mu \mathrm{g} /$ $\mathrm{mL}$ ). Cytotoxicity revealed time-dependent growth inhibition of cancer cells. However, treatment with ethanol extract shows concentration dependent apoptotic cells. The present result and also other recent report clearly exhibited that the $S$. marginatum having potential antibacterial and antioxidant as well as cytotoxic properties.
\end{abstract}

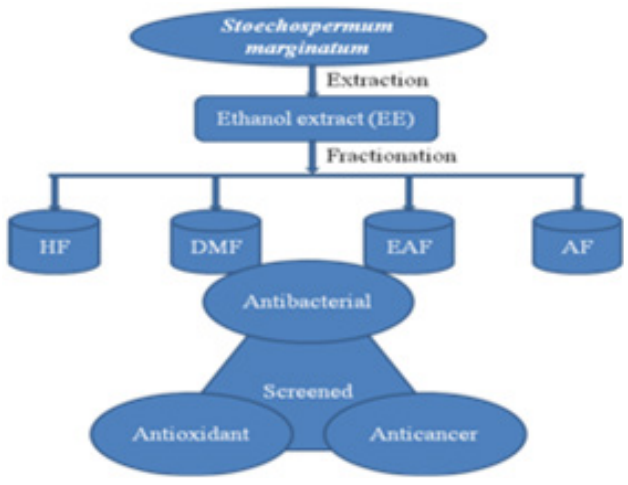

Keywords: ethanol extract, stoecheospermum marginatum,antibacterial antioxidant cytotoxicity
Volume 5 Issue 4 - 2017

\author{
Arumugama P, Murugan M, Kamalakannan S, \\ Murugan $\mathrm{K}$ \\ 'Department of Zoology, School of Life Science, Bharathiar \\ University, India \\ ${ }^{2}$ Department of Microbial Technology, Madurai Kamaraj \\ University, India
}

Correspondence: Ponnan Arumugam, School of Life Science, Bharathiar University, Coimbatore-4I 046,Tamil Nadu, India,Tel -8939432929, Email ponnanarumugam@gmail.com

Received: June 29, 2017 | Published: July 12, 2017
Abbreviations: HF, hexane; DMF, dichloromethane; EAF, ethyl acetate; $\mathrm{AF}$, aqueous fractions

\section{Introduction}

In general, all organisms undergoes oxidation process for the production of energy to stroll biological cycles. Consequently, over production of oxygen-derived free radicals is involved in the commencement of diseases like arthritis, atherosclerosis, and cancer as well as in many aging-related degenerative diseases. Cancer is one of the most serious threats against human health and also has done extensive research to the development of an overabundance of chemotherapeutic agents. However, none of these agents are capable of completely eliminating cancer. ${ }^{1}$ On other hand, many drug resistance mechanisms in human pathogenic microorganisms have developed because of the arbitrary use of known antibacterial drugs against infectious diseases. Therefore, novel compounds encompassing both antioxidants, antimicrobial and anticancer activities would be of great commercial value to the pharmaceutical industries today. This strategy can be fulfilled by the use of marine algae which has been proven to be effective in prevention of cancer as well as cardiovascular and degenerative diseases. ${ }^{2}$
Brown seaweed (Phaephyceae) is the largest and most complex group of algae having brown, olive or yellowish brown in colour. They are broadly distributed from tropical to polar zones of ocean in the world. ${ }^{3}$ It is known to contain most of the bioactive compounds including pigments, fucoidans, phycocolloids and phlorotannins than red and green seaweeds therefore mainly used as human food sources. ${ }^{4,5}$ However, phytochemical composition of the macro algae vary depending on, geographical distribution, habitats, maturity, seasons and the principal environmental conditions, such as water, temperature, salinity, light, and nutrients..$^{5}$ The brown algae Stoecheospermum marginatum distributed from Indian Ocean to Australian ocean. It was collected from the Gulf of Mannar near Mandapam coast $\left(9^{\circ} 16^{\prime} \mathrm{N}, 79^{\circ} 12^{\prime} \mathrm{E}\right)$ Tamilnadu, India during May 2015. It is potentially utilized as a food in salads, drugs, fresh meal for breeding form animals, manure for cultivation of vegetable and raw material for production of high percentage of alginic acid and mannitol. ${ }^{6}$ Various essential oils along with antioxidant and antibacterial potential were also documented in the methanolic and dichloromethane (1:1) extract of $S$. marginatum. ${ }^{7}$ Also, more secondary metabolites found inS. marginatum and reported to be enhanced peroxidase, phenyl alanine lyase, catalase, and poly phenol oxidase activities. ${ }^{8}$ Biological activity of spatane derivatives obtained 
from S. marginatum was well regarded. ${ }^{1}$ Hence, in the present study aimed to screen antibacterial and antioxidant activities of ethanol extract and its fraction of $S$. marginatum and also anticancer properties in HepG2 cell line studied by analyzing cytotoxicity using MTT assay and apoptosis by flowcytometer.

\section{Materials and methods}

\section{Chemicals}

ABTS, Annexin- V-FITC assay kit, MTT, SDS, quercetin, $\beta$-carotene and ascorbic acid were obtained from Sigma-Aldrich, USA. Potassium per sulfate obtained from Sisco Research Laboratory Pvt. Ltd. India. RPMI-1640, MHA, EDTA and DMSO were also obtained from Hi-mediai, India. All solvents used in this study were of analytical grade.

\section{Ethanol extraction and fractionation}

Stoechospermum marginatum (J. Agardh) Kuetz was collected from Gulf of Mannar, Mandapam, Southeast Coast of Tami Nadu, India. Sample process, extraction and fractionation were carried out as like our previous report. ${ }^{9}$ The yield of ethanol extract was obtained about 20g (8\%) whereas hexane (HF) dichloromethane (DMF) and ethyl acetate (EAF) and aqueous fractions (AF) were about $25 \%$, $35 \%, 30 \%$ and $10 \%$ respectively.

\section{Screening of phytonutrients}

The major phytonutrients such as alkaloids, tannins, saponins, terpenoids, phenols, flavonoids, coumarin, glycosides, reducing sugar, steroids and resins were spectrophotometrically screened in ethanol extract of $S$. marginatum according to the method of Allen ${ }^{10}$ and Harbone. ${ }^{11}$

Antibacterial activity was measured using a disc diffusion method described by Mackeen et al., ${ }^{12}$ Standard antibiotic, streptomycin was used as positive control. Ethanol extract and its solvent fractions $(100 \mu \mathrm{g})$ were loaded onto each disc $(6 \mathrm{~mm}$ diameter) and placed on previously inoculated agar plate with clinically important both gram positive and negative bacteria. The plates were incubated for $24 \mathrm{~h}$ at $37 \mathrm{oC}$.Diameter of zone inhibition around the disc were measured and expressed as in millimeter.

\section{Total antioxidant assay}

The detail description about $\mathrm{ABTS}^{+}$radical generation and quantification were given in our earlier article..$^{13,14}$ The radical assay performed with total of $1 \mathrm{~mL}$ reaction volume. ABTS. ${ }^{+}$radical scavenging potential of EE, HF, DMF, EAF and AF were tested with $0-160 \mu \mathrm{g} / \mathrm{mL}$ of concentration. The known standard antioxidants like quercetin, $\beta$-carotene and L-ascorbic were also used and their TAA utilized to make RAA of EE, HF, DMF, EAF and AF. Appropriate blanks were run in each assay. All the experiments were carried out in five replications and the values were averaged. The TAA and RAA were calculated and expressed based on our previous study. ${ }^{14}$

\section{Cytotoxicity assay}

MTT assay was performed by the method of Mosmann ${ }^{15}$ to determine the cytotoxicity of EE, HF, DMF, EAF and AF. MTT solution $(0.5 \mathrm{mg} / \mathrm{mL})$ was freshly prepared in PBS and used. $1 \times 1 \mid 0^{5}$ cells were seeded in 96-well plates and allowed to adhere for $6 \mathrm{~h}$. Later, cells treated with $0-640 \mu \mathrm{g} / \mathrm{mL}$ of EE, HF, DMF, EAF and $\mathrm{AF} /$ quercetin after filtered through $0.2 \mu$ Millipore filter and kept for 24 and $48 \mathrm{~h}$. Consequently, MTT solution $(100 \mu \mathrm{L})$ added in each well. The plates were incubated at $5 \% \mathrm{CO}_{2}$ incubator for $4 \mathrm{~h}$. The formazan crystals dissolved in $100 \mu \mathrm{L}$ of $20 \%$ SDS and the measured optical density (OD) using a microplate reader at $570 \mathrm{~nm}$. The inhibition ratio (I\%) calculated using the following equation: $\mathrm{I} \%=($ control- treated $) /$ control $\times 100 \%$ ).

\section{Annexin V-FITC assay}

The assay was performed according to the manufacture's protocol. Briefly, cells were seeded into 96-well plates and incubated for $48 \mathrm{~h}$ with different concentration $(0-640 \mu \mathrm{g} / \mathrm{mL})$ of EE and quercetin. Cells $\left(1 \times 10^{6} \mathrm{cells} / \mathrm{mL}\right)$ washed twice with PBS and resuspended in $500 \mu \mathrm{L}$ of binding buffer containing $5 \mu \mathrm{L}$ of FITC conjugated annexin-V and $5 \mu \mathrm{L}$ of PI. The plates were incubated in the dark for $15 \mathrm{~min}$ at ambient temperature and after analyzed by flowcytometry within a $1 \mathrm{~h}$ period. The percentage of total apoptotic cells was calculated by the addition of both early and late apoptotic evens. ${ }^{16}$

\section{Statistical analysis}

The results were expressed as a mean $\pm \mathrm{SD}$ with three or five values. All the data were analyzed statistically by One-way ANOVA and also correlation using SPSS software student's version-16. A $p$ value $<0.05$ was considered statistically significant.

\section{Results}

Exacted shade dried powder of Stoechospermum marginatum was directly immersed with ethanol solvent and extracted with Soxhlet apparatus. In term of secondary metabolites intrinsically presence in ethanol extract: alkaloids, tannins, saponins, triterpenoids, glycosides, phenols, Flavonoids, sterols, carbohydrates, proteins, fats and steroids. Ethanol extract was further fractionated with sequential solvents such as hexane, dichloromethane, ethyl acetate, and water. Ethanol extract and its solvent fractions were used to determine their antibacterial, total antioxidant and anticancer properties.

Antibacterial activity of ethanol extract and its solvent fractions/ standard, streptomycin were studied by disc diffuse method with nine clinically important bacteria. The highest antibacterial activity was found in ethanol extract followed by dichloromethane, ethyl acetate, hexane and aqueous fractions. Ethanol extract exhibited 14$27 \mathrm{~mm}$ in diameter zone of inhibition whereas other fractions such as dichloromethane, ethyl acetate, hexane and aqueous fractions showed in the range of $11-24,9-16,8-13$ and $5-7 \mathrm{~mm}$ in diameter zone of inhibition, respectively. Antibacterial activity of ethanol extract was observed to be more comparable to the standard of streptomycin (Table 1).

TAAs and RAAs were estimated in ethanol extract and its four fractions along with known antioxidant such as quercetin, $\beta$-carotene and L-ascorbic acid (Table 2). TAA of solvent fractions were tested using $20-160 \mu \mathrm{g} / \mathrm{mL}$ concentrations whereas RAA calculated with maximum TAA of quercetin, $\beta$-carotene and L-ascorbic acid. TAA was found to be in the range of $22-75 \%$ in EE, $8-38 \%$ in HF, $18-65 \%$ in DMF, $13-50 \%$ in EAF and $5-31 \%$ in AF. The maximum TAA was obtained $75 \%$ at the $160 \mu \mathrm{g} / \mathrm{mL}$ concentration of $\mathrm{EE}$ and least $5 \%$ at the $10 \mu \mathrm{g} / \mathrm{mL}$ concentration of AF. TAA of DMF exhibited significantly over the HF, EAF and AF. Similarly, the RAA was also found to be the same as like as TAA. The maximum RAA was observed $\geq 1$ in the EE followed by DMF, EAF, HF and AF against in both standard antioxidants. R square value made between concentration and TAA of extract/fractions by linear regression clearly shows \% TAA dependents on the concentration.

Cytotoxicity of EE and its solvent farctions of S. marginatum were tested by MTT assay. The cancer cells showed considerable and dose 
dependent susceptibility to the EE and its solvent fractions (160$640 \mu \mathrm{g} / \mathrm{mL}$ ) along with standard of quercetin. Cytotoxicity of EE was found to be $23-59 \%$ and $40-80 \%$ followed by $18-47 \%$ \& $35-68 \%$ in DMF, $15-40 \%$ \& $30-63 \%$ in EAF, $10-30 \%$ \& $18-46 \%$ in HF, $6-21 \%$ \& $17-33 \%$ in AF where as quercetin $25-63 \%$ and $46-85 \%$ at the $24 \mathrm{~h}$ and
$48 \mathrm{~h}$ of time intervals, respectively. Moreover, ethanol extract exhibited cytotoxicity as equal as quercetin at their maximum concentration $(640 \mu \mathrm{g} / \mathrm{mL}$ and $160 \mu \mathrm{g} / \mathrm{mL})$. Cytotoxicity revealed time-dependent growth inhibition of cancer cells (Table 3).

Table I TAA and RAA of ethanol extract and its solvent fractions of S. marginatum

\begin{tabular}{|c|c|c|c|c|c|c|}
\hline \multirow[t]{2}{*}{ Solvent extract and fractions } & \multirow[t]{2}{*}{ Conc. $(\mu \mathrm{g} / \mathrm{mL})$} & \multirow[t]{2}{*}{ TAA (\%) } & \multirow[t]{2}{*}{ R2 value } & \multicolumn{3}{|l|}{ RAA } \\
\hline & & & & Quercetin & Ascorbic acid & $\beta$-carotene \\
\hline \multirow[t]{4}{*}{ EE } & 20 & $22 \pm 2.00$ & 0.835 & 0.27 & 0.29 & 0.29 \\
\hline & 40 & 443.16 & & 0.54 & 0.59 & 0.57 \\
\hline & 80 & $62 \pm 3.46$ & & 0.76 & 0.83 & 0.81 \\
\hline & 160 & $75 \pm 4.12$ & & 0.92 & I & 0.97 \\
\hline \multirow[t]{4}{*}{$\mathrm{HF}$} & 20 & $08 \pm 1.87$ & 0.971 & 0.1 & 0.11 & 0.1 \\
\hline & 40 & $13 \pm 1.00$ & & 0.16 & 0.17 & 0.17 \\
\hline & 80 & $25 \pm 3.16$ & & 0.31 & 0.33 & 0.32 \\
\hline & 160 & $38 \pm 4.69$ & & 0.46 & 0.51 & 0.49 \\
\hline \multirow[t]{4}{*}{ DMF } & 20 & $18 \pm 2.24$ & 0.902 & 0.22 & 0.24 & 0.23 \\
\hline & 40 & $33 \pm 3.81$ & & 0.4 & 0.44 & 0.43 \\
\hline & 80 & $48 \pm 4.69$ & & 0.59 & 0.64 & 0.62 \\
\hline & 160 & $65 \pm 4.30$ & & 0.79 & 0.87 & 0.84 \\
\hline \multirow[t]{4}{*}{ EAF } & 20 & $13 \pm 1.00$ & 0.919 & 0.16 & 0.17 & 0.17 \\
\hline & 40 & $23 \pm 2.24$ & & 0.28 & 0.31 & 0.3 \\
\hline & 80 & $37 \pm 4.69$ & & 0.45 & 0.49 & 0.48 \\
\hline & 160 & $50 \pm 4.47$ & & 0.61 & 0.67 & 0.65 \\
\hline \multirow[t]{4}{*}{$\mathrm{AF}$} & 20 & $05 \pm 1.58$ & 0.973 & 0.06 & 0.07 & 0.07 \\
\hline & 40 & $\mathrm{II} \pm 2.24$ & & 0.13 & 0.15 & 0.14 \\
\hline & 80 & $20 \pm 2.24$ & & 0.24 & 0.27 & 0.26 \\
\hline & 160 & $31 \pm 4.95$ & & 0.38 & 0.41 & 0.4 \\
\hline
\end{tabular}

Percentage mean + SD ( $n=5)$; TAA: Total Antioxidant Activity; RAA = Relative Antioxidant Activity; RAA computed TAA of solvent fraction divided by TAA of standards (Quercetin $82 \% 5 \mu \mathrm{M} / \mathrm{ml}$, b-Carotene: $77 \% 7.5 \mu \mathrm{M} / \mathrm{ml}$ and L.Ascorbic acid: $72 \%$ 20 $\mu \mathrm{M} / \mathrm{ml}$ ). R square value obtained between concentration and \%TAA by Linear regression.

Table 2 Ethanol extract and its solvent fractions of S. marginatum on human pathogenic bacteria

\begin{tabular}{|c|c|c|c|c|c|c|}
\hline Organism Name & EE & HE & DMF & EAF & AF & Streptomycin \\
\hline Bacillus subtilis & $21 \pm 1.00$ & $\mathrm{II} \pm \mathrm{I} .53$ & $18 \pm 1.53$ & $15 \pm 1.00$ & - & $30 \pm 4.00$ \\
\hline Escherichia coli & $27 \pm 2.52$ & $12 \pm 1.53$ & $24 \pm 2.00$ & $14 \pm 1.53$ & - & $26 \pm 3.00$ \\
\hline Enterococcus faecalis & $19 \pm 1.25$ & $08 \pm 1.63$ & $15 \pm 1.63$ & $14 \pm 1.63$ & - & $21 \pm 1.25$ \\
\hline Klebsiella pneumoniae & $18 \pm 1.53$ & $08 \pm 0.58$ & $15 \pm 1.00$ & $09 \pm 1.53$ & $05 \pm 2.00$ & $22 \pm 3.22$ \\
\hline Pseudomonas aeruginosa & $17 \pm 2.00$ & - & $12 \pm 1.53$ & $09 \pm 1.00$ & - & $2 I \pm 4.5 \mid$ \\
\hline Salmonella typhi & $20 \pm 1.00$ & $10 \pm 1.53$ & $17 \pm 2.08$ & $12 \pm 2.00$ & $05 \pm 1.53$ & $28 \pm 2.64$ \\
\hline Salmonella paratyphi & $22 \pm 2.06$ & $\mathrm{II} \pm \mathrm{I} .25$ & $21 \pm 1.70$ & $16 \pm 2.62$ & $07 \pm 1.25$ & $29 \pm 2.06$ \\
\hline Staphylococcus aureus & $23 \pm 2.52$ & $13 \pm 2.00$ & $19 \pm 1.53$ & $14 \pm 2.00$ & - & $28 \pm 5.86$ \\
\hline Vibrio cholerae & $14 \pm 1.63$ & - & $\mathrm{II} \pm \mathrm{I} .25$ & - & $05 \pm 0.47$ & $15 \pm 2.16$ \\
\hline
\end{tabular}

Results expressed as a mean (mm diameter of zone inhibition) \pm SD ( $n=3)$; EE: Ethanol Extract; HF: Hexane Fraction; DMF: Dichloromethane Fraction; EAF: Ethyl Acetate Fraction;AF:Aqueous Fraction.

Table 3 Cytotoxicity of ethanol extract and its solvent fraction of S. marginatum on HepG2 cell line

\begin{tabular}{|c|c|c|c|c|c|c|}
\hline \multirow[t]{2}{*}{$\begin{array}{l}\text { Standard/ Extract / } \\
\text { Fraction }\end{array}$} & \multicolumn{3}{|c|}{$\%$ Cytotoxicity at $24 \mathrm{~h}$} & \multicolumn{3}{|c|}{$\%$ Cytotoxicity at $\mathbf{4 8 h}$} \\
\hline & $40 / 160 \mu \mathrm{g} / \mathrm{mL}$ & $80 / 320 \mu \mathrm{g} / \mathrm{mL}$ & $160 / 640 \mu \mathrm{g} / \mathrm{mL}$ & $40 / 160 \mu \mathrm{g} / \mathrm{mL}$ & $80 / 320 \mu \mathrm{g} / \mathrm{mL}$ & $160 / 640 \mu \mathrm{g} / \mathrm{mL}$ \\
\hline Quercetin & $25 \pm 4.36$ & $45 \pm 7.55$ & $63 \pm 6.25$ & $46 \pm 7.00$ & $67 \pm 4.59$ & $85 \pm 5.00$ \\
\hline $\mathrm{EE}$ & $23 \pm 2.00$ & $40 \pm 5.57$ & $59 \pm 3.61$ & $40 \pm 7.00$ & $59 \pm 5.00$ & $80 \pm 2.65$ \\
\hline $\mathrm{HE}$ & $10 \pm 2.00$ & $15 \pm 2.00$ & $30 \pm 3.61$ & $18 \pm 2.00$ & $32 \pm 4.00$ & $46 \pm 3.61$ \\
\hline DMF & $18 \pm 2.00$ & $28 \pm 5.57$ & $47 \pm 3.61$ & $35 \pm 7.00$ & $5 I \pm 5.00$ & $68 \pm 2.65$ \\
\hline EAF & $15 \pm 2.00$ & $22 \pm 2.00$ & $40 \pm 3.61$ & $30 \pm 2.00$ & $46 \pm 4.00$ & $63 \pm 2.65$ \\
\hline $\mathrm{AF}$ & $06 \pm 1.00$ & $13 \pm 1.73$ & $21 \pm 1.00$ & $17 \pm 2.00$ & $24 \pm 2.00$ & $33 \pm 2.65$ \\
\hline
\end{tabular}

Results expressed as a percentage mean $\pm S D(n=3)$; EE: Ethanol Extract; HF: Hexane Fraction; DMF: Dichloromethane Fraction; EAF: Ethyl Acetate Fraction;AF: Aqueous Fraction. 
The total apoptotic cells including addition of early and late apoptosis were observed after $48 \mathrm{~h}$ treatment with ethanol extract of $S$. marginatum using annexin V-FITC assay kit (Figure 1). Ethanol extract showed statistically $(p<0.05)$ significant increase of apoptotic cells than that of quercetin $(35 \%, 160 \mu \mathrm{g} / \mathrm{mL})$. Ethanol extract enhanced total apoptotic cells in range of $11-47 \%$ at the $160-640 \mu \mathrm{g} /$ $\mathrm{mL}$ of concentrations. However, treatment with ethanol extract shows concentration dependent apoptotic cells.

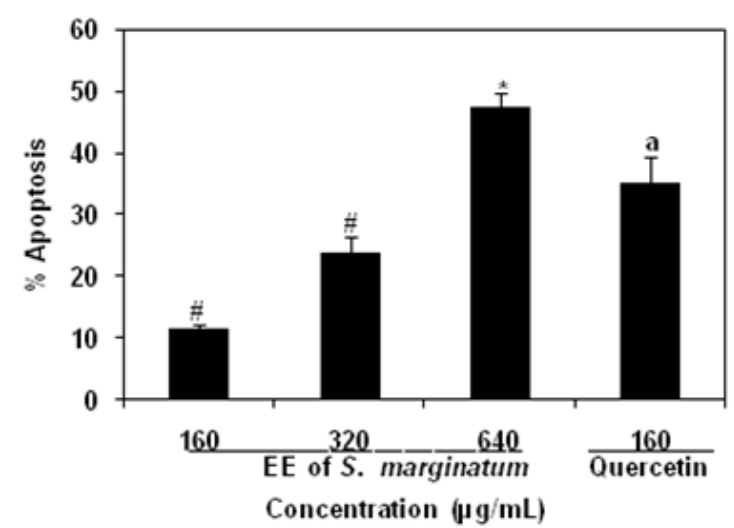

Figure I Ethanol extract of S. marginatum induced apoptosis in HepG2 cell line.

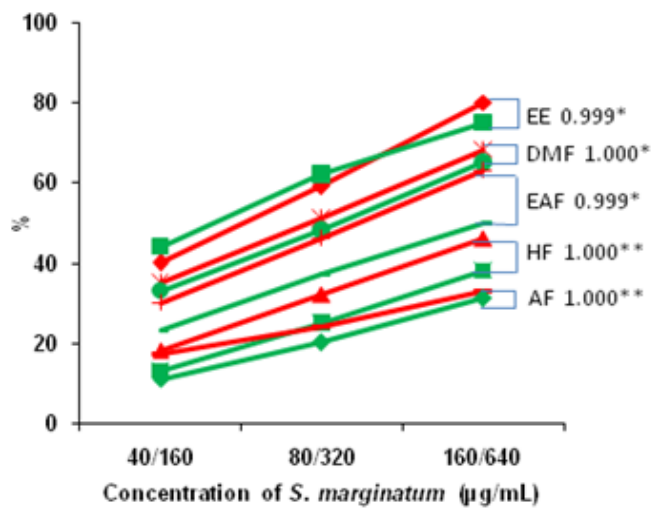

Figure 2 Correlation between the percentage of antioxidant and cytotoxicity of ethanol extract of S. marginatum.

Green line: TAA; Red line: cytotoxicity; EE: Ethanol Extract; HF: Hexane Fraction; DMF: Dichloromethane Fraction; EAF: Ethyl Acetate Fraction; AF: Aqueous Fraction.

\section{Discussion}

In the present study was undertaken to exhibite the antibacterial and antioxidant activities of $S$. marginatum along with their cytotoxicity through MTT assay in HepG2 cell line. It is well known that Brown seaweeds having most important phytonuctrients including pigments, fucoidans, phycocolloids and phlorotannins. ${ }^{5}$ However, ethanol extract of $S$. marginatrum obsessed following phytonutrients intrinsically alkaloids, tannins, saponins, triterpenoids, glycosides, phenols, Flavonoids, sterols, carbohydrates, proteins, fats and steroids (Table 1). Clinically important gram-positive and gram-negative bacteria were tailored to screen the antibacterial activity of $S$. marginatum. Results clearly exhibited that the ethanol extract of $S$. marginatum showed positive response against all the tested bacterial than that of their subtractions which was furthermore comparable to known antibiotics of streptomycin. The inhibitory zone by ethanol extract was found to be $17-27 \mathrm{~mm}$ whereas streptomycin 21-30mm. However, both ethanol extract and standard were shown less antibacterial activity against Vibrio cholera. Among the fractions, DMF showed better antibacterial response $11-24 \mathrm{~mm}$ of diameter of zone inhibition followed by EAF. However, HF and AF did not shown better response among the tested bacteria's. The later results was similar to our previous study that $\mathrm{AF}$ of $T$. conoides did not exhibit antibacterial response against $50 \%$ of bacteria tested. ${ }^{10}$ In addition, antibacterial activity of ethanol, methanol, chloroform and hexane extracts of $S$. marginatum clearly reported against seven Gram-positive and Gram-negative bacteria. Among them, ethanol extract was found highest antibacterial activity and hexane lowest. ${ }^{2}$ Antibacterial activity of $S$. marginatum was mainly due to the various phytonutrients like triterpenoids, phenolics, spatane derivatives and etc., which may affect growth and metabolism of bacteria. ${ }^{1}$ Antibacterial activity of ethanol extract of $S$. marginatum was also recorded using both gram positive and negative bacteria's. ${ }^{16}$

Total antioxidant activity of ethanol extract and its factions, HF, DMF, EAF and AF were exhibited in the Table 1. Among them, EE showed highest TAA $(75 \%, 160 \mu \mathrm{g} / \mathrm{mL})$ than that of their fractions: $38 \% \mathrm{HF}, 65 \% \mathrm{DMF}, 50 \% \mathrm{EAF}$ and $31 \% \mathrm{AF}$ at the $160 \mu \mathrm{g} / \mathrm{mL}$. EE having 2, 1.2, 1.5 and 2.4 fold higher TAA than that of HF, DMF, EAF and AF, respectively. Even TAA at $20 \mu \mathrm{g} / \mathrm{mL}$ of EE was better than that of their fractions. At the maximum concentration, TAA of EE was comparable to the standard of $\beta$-carotene $(77 \% 7.5 \mu \mathrm{M} / \mathrm{ml})$ and ascorbic acid $(72 \% 20 \mu \mathrm{M} / \mathrm{ml})$. TAA of DMF was showed $(65 \%$, $160 \mu \mathrm{g} / \mathrm{mL}$ ) second highest than that of HF EAF and AF. However, $\mathrm{R}$ square value of $\mathrm{EE}$ and its fractions clearly revealed that TAA was dependent to their concentration (Table 1). Moreover, EE alone expressed RAA $\geq 1$ against ascorbic acid when compared to their fractions. The results revealed that EE explored potential antioxidant activity than that of their fractions. The recent report exhibited that methanolic extract of $S$. marginatum having high content of phenolic which was explored effective antioxidant, metal ion chelation and cytotoxicity properties. ${ }^{17}$ Antioxidant activity of methanol, chloroform and hexane extract of $S$. marginatum were reported to posses radical scavenging activity through both electron and hydrogen transfer mechanisms. $^{2}$

MTT assay used for testing cytotoxicity of plant extracts because of their easy handling, inexpensive and more rapid bioassay that can be extrapolated in cell-line toxicity and antitumor activity. Cytotoxicity considered as the cell killing property of a phytonutrients which is independent mechanism from the programmed cell death. ${ }^{18}$ The finding explored better cytotoxicity was observed in EE (80\%) than that of their fractions and also significantly $(\mathrm{p} \leq 0.05)$ comparable to the standard of quercetin (85\%). Cytotoxicity of EE $(640 \mu \mathrm{g} / \mathrm{mL}$ at 48h) was showed 1.7, 1.2, 1.3 and 2.4 fold higher activity than that of $\mathrm{HF}, \mathrm{DMF}, \mathrm{EAF}$ and AF, respectively. The second highest cytotoxicity was found $(68 \% 640 \mu \mathrm{g} / \mathrm{mL}$ at $48 \mathrm{~h})$ in DMF of S. marginatum which better than that of other fractions. Hence, correlation between TAA and cytotoxicity of $S$. marginatum was made to explore significance of the parameter (Figure 1). EE and EAF significantly $(p \leq 0.05)$ correlated $(0.999)$ whereas other fractions more significantly $(\mathrm{p} \leq 0.01)$ correlated (1.000). Statistical data revealed that TAA and cytotoxicity of $S$. marginatum were found to be well correlated along with concentration. Cytotoxicity of various extract obtained from a variety algae collectively demonstrated that the brown algae have a potential source of compounds presenting biological activities on tumor cells. ${ }^{19}$ Recent report demonstrated that $S$. marginatum methanol extract powerfully inhibits cell proliferation of EAT and BeWo cells and less effect on non transformed HEK 293 cells. It was mainly due to the presence of phenols, tannins, saponins, cardiac glycosides, alkaloids, anthraquinones, and flavonoides in their extracts. ${ }^{20}$ 
Total apoptosis of EE of $S$. marginatum on HepG2 cell line were determined using annexin V-FITC and PI staining. Annexin-V $(35-36 \mathrm{kDa}) \mathrm{Ca}^{2+}$ dependent phospholipid binding protein have high affinity towards phosphatidyl serine which is located on the cytoplasmic surface of the normal cell whereas in apoptotic cells, located in the outer leaflet of the plasma membrane. In addition, the red-fluorescent PI is a nucleic acid binding dye which is impermeant to live cells and early apoptotic cells but stains dead cells with red fluorescence. After staining a cell population with annexin V and PI, apoptotic cells shows green fluorescence, dead cells shows red and green fluorescence, and live cells shows little or no fluorescence ${ }^{9}$. EE of $S$. marginatum showed $(47 \%, 640 \mu \mathrm{g} / \mathrm{mL})$ statistically $(p<0.05)$ significant increase of apoptotic cells than that of quercetin standard $(35 \%, 160 \mu \mathrm{g} / \mathrm{mL})$. The maximum concentration of EE enhanced 4.3 fold of apoptotic cells over the lower concentration $(160 \mu \mathrm{g} / \mathrm{mL})$. Thus, the result shows that the total apoptotic cells were found to be concentration dependent and better than that of quercetin (Figure 2).

\section{Conclusion}

It is well known that the brown algae contain enormous bioactive compounds than that of other macro algae like red and green seaweeds. Essentially, brown seaweeds widely utilized as a food, drugs, fertilizer and raw material for alginic acid and mannitol production. There was research finding revealed about antibacterial and antioxidant activities of $S$. marginatum against different expediency methods. However, cytotoxicity of $S$. marginatum against hepatocellular carcinoma was scanty. Summary of results confirmed that ethanol extract of $S$. marginatum contained rich phytonutrients through it was exhibited highest antibacterial, TAA and RAA over their fractions such as HF, DMF, EAF and AF. In addition, in-vitro anticancer activity of $S$ marginatum exploredthrough exhibiting $23-80 \%$ cytotoxicity, $11-$ $47 \%$ of apoptosis. Recent report stated that $S$. marginatum having good antioxidant, antifungal, and antibacterial as well as cytotoxic activities. Also, a differential anti-microbial \& anticancer property of $S$. marginatum was due to their phytonutrients and its analog against bacterial strains and cell lines (B16F10, U937, THP-1, COLO205 and HL60). ${ }^{1}$ Further studies are needed to identify bioactive molecules in the ethanol extract and evaluated its mechanisms in an animal model.

\section{Acknowledgments}

This contributed research work was supported by University Grant Commission (UGC), Government of India, New Delhi (TAM -8496).

\section{Conflicts of interest}

There was no conflict of interest.

\section{Funding}

None.

\section{References}

1. Chinnababu B, Purushotham Reddy S, Sankara Rao P, et al. Isolation, semi-synthesis and bio-evaluation of spatane derivatives from the brown algae Stoechospermum marginatum. Bioorg Med Chem Lett. 2015;25(12):2479-2483.

2. Akbar E, Khakpoor M. Biological activities and chemical composition of solvent extracts of Stoechospermum marginatum(C. Agardh).Acta Bio Pol. 2012;59(4):581-585.

3. Indrawati $\mathrm{R}$, Sukowijoyo $\mathrm{H}$, Indrriatmoko Wijayanti $\mathrm{DE}$, et al. Encapsulation of brown seaweed pigment by freeze drying characterization and its stability during storage. Procedia chemistry. $2015 ; 14: 353-360$
4. Rajamani K, Somasundaram ST, Manivasagam T, et al. Hepatoprotective activity of brown alga Padina boergesenii against CCL4 induced oxidative damage in wistar rats. Asia Pac J trop Med. 2010. p.696-701.

5. El-Said GF, El-Sikaily A. Chemical composition of some seaweed from Mediterranean Sea coast, Egypt. Env Monit Asses. 2013;185(7):6089-6099.

6. Reka P, Thahira BA, Seethalakshmi M. Nutrient Content, Phytonutrient Composition, Alpha Amylase, Alpha Glucosidase Inhibition Activity and Antioxidant Activity of the Stoechospermum Marginatum Collected in Pre Monsoon Season. Turkish JAF Sci Tech. 2017;5(3):275-280.

7. Anbu A, Arun E, Selvakumari Gopal V. Phytochemical and Pharmacological Profile of Brown Marine Algae Stoecheospermum marginatum. J Acad Indus Res . 2017;5(8):120-122.

8. Flora G, Maria Victorial Rani S. Effect of Stoechospermum marginatum $(\mathrm{Ag})$. Kutz extract on controlling blast disease in rice caused by Pyricularia oryzae under natural field condition. Afr J Agric Res. 2013;8(25):3289-3293.

9. Arumugam P, Murugan K, Kavipriya R, et al. Antibacterial, antioxidant and anticancer properties of Turbinaria conoides (J. Agardh) Kuetz. Clinical Phytoscience . 2017;3:5-10.

10. Allen ST. Chemical analysis of ecological material. Blackwell Scientific Publication, New York, USA. 1974. p.313.

11. Harbone JR. Phytochemical methods. A guide to modern techniques of plant analysis. Charpan and Hall, London, UK. 1976. p.78.

12. Mackeen MM, Ali AM, El-sharkawy SH, et al. Antimicrobial and cytotoxic properties of some Malaysian traditional vegetables. International Journal of Pharmacognosy. 1997;35(3):174-178.

13. Arumugam P, Ramamurthy P, Santhiya ST, et al. Antioxidant activity measured in different solvent fractions obtained from Mentha spicata Linn.: ananalysis by ABTS.+ decolorization assay. Asia Pa. $J$ Clin Nutr. 2006;15(1):20-24.

14. Arumugam P, Ramamurthy P, Ramesh A. Antioxidant and cytotoxic activities of lipophilic and hydrophilic fractions of Mentha spicata L. (Lamiaceae). International Journal of Food Properties. 2010;13(1):23-31.

15. Mosmann TJ. Rapid colorimetric assay for cellular growth and survival: Application to proliferation and cytotoxicity assays. J Imm Meth 1983;65(1-2):55-63.

16. Radhika D, Veerabahu C, Priya R, et al. A comparative study of biopotential of crude and fractionated extracts of some sea weeds from Tuticorin coast. Int J Phytopharmacol. 2014;5(1):27-30.

17. Rashmi C, Vinayak A, Sabu S, et al. Bio-Prospecting of a Few Brown Seaweeds for Their Cytotoxic and Antioxidant Activities. Evid. Based Comple. Evidence-Based Complementary and Alternative Medicine. 2011;11:1-9.

18. Jin X, Chen Q, Tang SS, et al. Investigation of quinocetone-induced genotoxicity in HepG2 cells using the comet assay, cytokinesisblock micronucleus test and RAPD analysis. Toxicol In Vitro 2009;23(7):1209-1214.

19. Gambato G, Caroline OS, Frozza, Érico G, et al. Brown Algae Himantothallus grandifolius(Desmarestiales, Phaeophyceae) Suppresses Proliferation and Promotes Apoptosis-Mediated Cell Death in Tumor Cells. Adv Biol Chem. 2014;4(2):98-108.

20. Rashmi V, Shilpa P, Anil C, et al. Anti-proliferative and angiosuppressive effect of Stoechospermum marginatum (C. Agardh) Kutzing extract using various experimental models. Nutr Res Pract . 2014;8(4):377-385. 